\title{
Bronchoscopic resection of bronchial angiolipoma: A rare case report
}

\author{
ZHIQIANG WU ${ }^{1}$, HONGLI WAN ${ }^{2}$, MIN SHI $^{3}$, MING LI $^{1}$, ZHANPENG WANG $^{1}$, \\ CAIXIA YANG ${ }^{1}$, WEI GAO ${ }^{1}$ and QINGXIN LI ${ }^{1}$
}

\author{
${ }^{1}$ Department of Thoracic Surgery, Lanzhou General Hospital of PLA, Lanzhou, Gansu 730050; ${ }^{2}$ Department of \\ Gynecology and Obstetrics, Sichuan Provincial Communications Department Highway Bureau Hospital, Chengdu, \\ Sichuan 611731; ${ }^{3}$ Department of Pathology, Lanzhou General Hospital of PLA, Lanzhou, Gansu 730050, P.R. China
}

Received December 14, 2015; Accepted October 20, 2016

DOI: $10.3892 /$ mco.2016.1069

\begin{abstract}
Angiolipoma is a rare benign tumor that most commonly occurs in the extremities and trunk. Angiolipomas originating in the bronchial tree are extremely rare. To the best of our knowledge, only one such case, confined to the bronchus intermedius, has been reported to date. The present study describes the case of an asymptomatic 74-year-old man with a yellowish round mass incidentally discovered at the orifice of the right lower bronchus during a routine health check. The tumor originated from the membranous part of the right inferior bronchus. Using a high-frequency electric snare and argon plasma coagulation under general anesthesia, successful bronchoscopic resection of the tumor was performed. At 15 months after the surgery, the patient remained recurrence- and symptom-free.
\end{abstract}

\section{Introduction}

Endobronchial lipomas are a rare benign tumors accounting for only $0.1 \%$ of all lung neoplasms (1). They are classified into lipoma, variants of lipoma, heterotopic lipomas, hamartomatous lesions, infiltrating or diffuse neoplastic or non-neoplastic proliferations of mature fat and hibernoma (2). Angiolipoma is a variant of lipoma accounting for $5-17 \%$ of all lipomas and predominantly presents in young adults as subcutaneous nodules, which are tender or painful on palpation, particularly during the initial growth period (1-4). Angiolipoma, however, arising in the bronchus, is extremely rare. To the best of our knowledge, only one such case has been reported to date,

Correspondence to: Professor Wei Gao or Professor Qingxin Li, Department of Thoracic Surgery, Lanzhou General Hospital of PLA, 333 Binhe South Road, Qilihe, Lanzhou, Gansu 730050, P.R. China E-mail: gaoweizy@126.com

E-mail: lqxchest@163.com

Key words: angiolipoma, endobronchial tumor, lung tumor, bronchoscopic resection, electrosurgical snaring, argon plasma coagulation which was confined to the bronchus intermedius (5). The present study describes a rare case of a 74-year-old man with a yellowish round mass incidentally discovered at the orifice of the right lower bronchus during a routine health check. The mass was resected using a high-frequency electric snare and argon plasma coagulation through a flexible bronchoscope under general anesthesia and was proven on histopathological examination to be an angiolipoma.

\section{Case report}

A 74-year-old man was referred to the Department of Thoracic Surgery of Lanzhou General Hospital (Lanzhou, China) for treatment of an endobronchial tumor that was incidentally discovered on chest radiography and computed tomography (CT) during a routine health check in another hospital, without symptoms. A chest CT revealed a round mass, sized $\sim 15 \times 12 \mathrm{~mm}$, occluding the lumen of the right inferior bronchus, with low attenuation (Fig. 1). Partial postobstructive pneumonia in the right lower lobe was also found on the CT scan. The patient underwent flexible bronchoscopy that confirmed the presence of a yellowish round pedunculated mass at the orifice of the right inferior bronchus, which was mobile during breathing and nearly occluded the bronchial lumen (Fig. 2). As it was difficult to obtain bioptic specimens from the mass and due to the risk of bleeding, pathological examination was not performed preoperatively. The patient had undergone radical resection of gastric carcinoma $\sim 10$ years prior, had been diagnosed with diabetes mellitus 1 year prior, and he was a heavy smoker. Physical examination and laboratory test results revealed no significant abnormalities.

Bronchoscopic resection of the lesion was performed during flexible bronchoscopy using a high-frequency electric snare under general anesthesia. The tumor originated from the membranous part of the right inferior bronchus. Following removal of the mass, additional argon plasma coagulation was performed to remove the residual tumor base and to control the bleeding. Histologically, the tumor contained adipose tissue and proliferative blood vessels, and was diagnosed as angiolipoma (Fig. 3).

The patient's postoperative recovery was uneventful and he was discharged on the third postoperative day. The patient has 


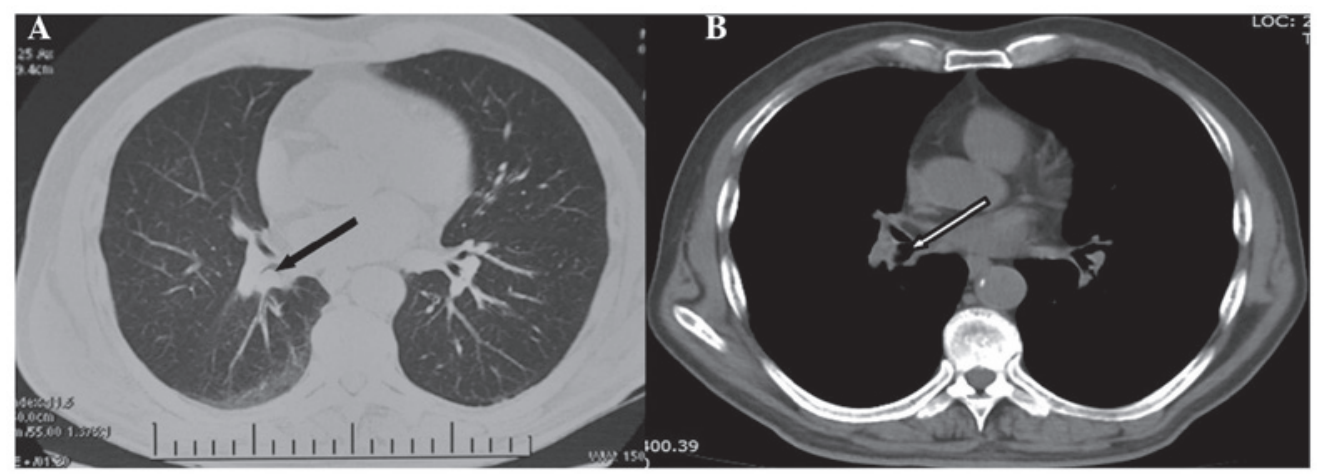

Figure 1. Chest computed tomography scan showing a round mass in the right inferior bronchus occluding the lumen (arrow). (A) Lung window and (B) mediastinal window.

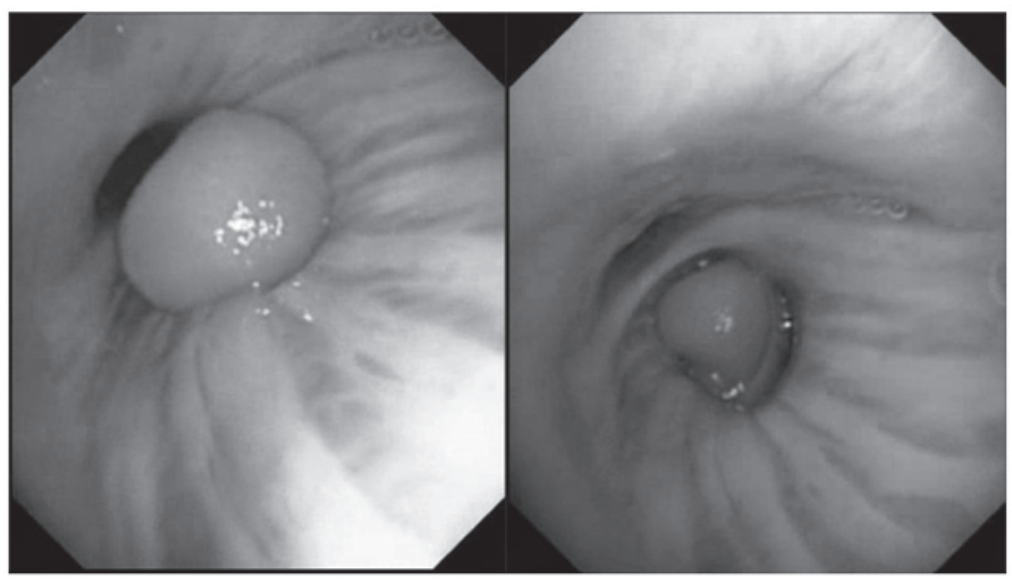

Figure 2. Bronchoscopy revealed a yellowish round pedunculated mass at the orifice of the right inferior bronchus, which was mobile during breathing and nearly occluded the bronchial lumen.

been followed up in the outpatient department for 15 months with no symptoms or recurrence.

Written informed consent was obtained from the patient and his family regarding the publication of the case details and associated images.

\section{Discussion}

Angiolipoma was first described as a multiple subcutaneous tumor and named by Bowen in 1912 (6). In 1960, Howard and Helwig (4) described the clinical and histological characteristics of angiolipomas that distinguish them from lipomas, thereby designating angiolipoma as a new entity. Through cytogenetic analysis, Sciot et al (7) demonstrated a normal karyotype of angiolipomas, in contrast to the various other types of benign lipomas, most of which exhibit rather characteristic clonal chromosomal aberrations, suggesting that the pathogenesis of angiolipoma differs from that of pure lipomas. Angiolipoma occurs most commonly in young patients in their second or third decades of life, and exhibits a male predominance (8). Gonzales-Crussi et al (9) recommended classifying angiolipomas into two subtypes, namely non-infiltrating and infiltrating. The non-infiltrating type is more common and is usually well-encapsulated, just as shown in the present case. The infiltrating tumors are partially or entirely unencapsulated, ill-defined and invade adjacent tissues (10).

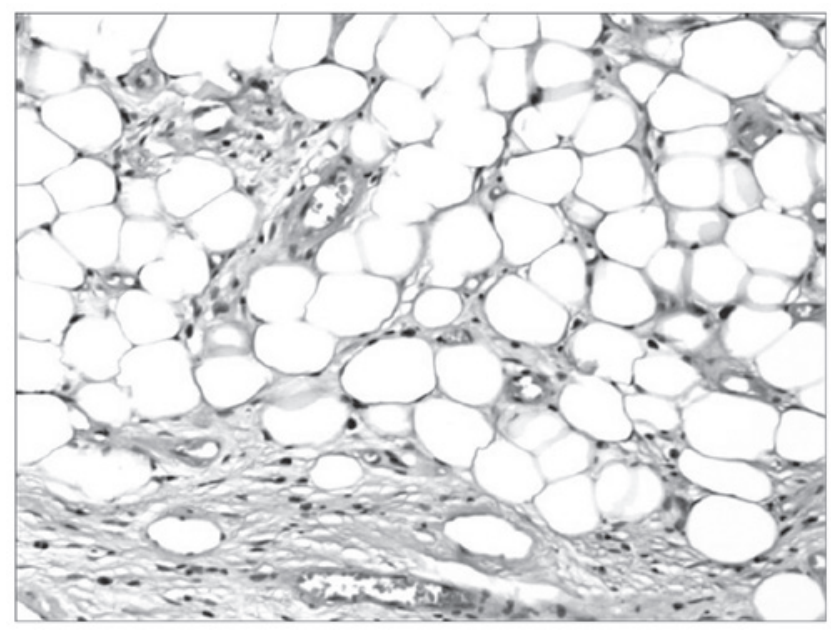

Figure 3. Histopathological examination of the resected tumor established the diagnosis of bronchial angiolipoma consisting of a combination of mature adipose tissue and multiple small blood vessels (hematoxylin and eosin staining; magnification, x100).

The pathogenesis of angiolipoma remains unclear. Trauma, smoking and obesity have been implicated as possible etiological factors $(11,12)$. Angiolipoma may also be hamartomatous in nature (12). The patient in the present case had no history of trauma and was not corpulent, but was a heavy smoker. 
Angiolipomas are mainly located in the subcutaneous tissues of the trunk and extremities, and are tender or painful on palpation. Unusual locations reported in the literature, however, include the brain, breast, intramedullary and epidural spine, foot, cheek, lip, mediastinum, mandible, ribs, palate, parotid gland and orbit (12-15). To the best of our knowledge, only one case of bronchial angiolipoma has been reported in the English literature to date (5). This neoplasm is usually slow-growing and presents with symptoms associated with bronchial obstruction. In our case, the patient was asymptomatic, as the mass was mobile and did not completely occlude the lumen.

In the present case, the lesion exhibited low attenuation in the bronchial lumen on CT examination. The differential diagnosis should include hamartoma and lipoma. Angiolipoma may be difficult to distinguish from hamartoma, unless calcifications are present in the hamartoma, or the ratio of dense vascular and stromal elements is significantly higher (16). The most characteristic diagnostic feature of angiolipoma is the presence of adipose tissue and angiomatous proliferation, as was the case in our patient.

Endobronchial angiolipoma may be resected by surgical or bronchoscopic methods. In the only previous report of bronchial angiolipoma, the authors performed successful localized resection of the lesion and suggested complete surgical resection was advisable if the patient was able to tolerate the procedure. However, some scholars consider bronchoscopic resection, which was employed in the present case, to be the preferred method, as rare benign tumors characterized by slow growth may carry a low risk of malignant transformation $(11,17,18)$. Endoscopic resection includes laser ablation, electrocauterization, cryorecanalization and electrosurgical snaring (19). Electrosurgical snaring and argon plasma coagulation are convenient and safe to use for removal of the lesion by flexible bronchoscopy under general anesthesia, as described in our case. It was agreed that adjuvant radiation should not be administered for this benign pathological entity, even in the infiltrating group (20).

The prognosis of angiolipoma following complete resection appears to be satisfactory. The patient described in the present case remained recurrence- and symptom-free at the 15-month follow-up; however, long-term survival remains to be assessed.

\section{References}

1. Weiss SW and Goldblum JR (eds). Benign lipomatius tumors. In: Enzinger and Weiss's Soft Tissue Tumors. 4th edition. Mosby, St Louis, MO, pp571-639, 2001
2. Ohnishi Y, Watanabe M,Fujii T, Yasui H, Kubo H and Kakudo K: Infiltrating angiolipoma of the lower lip: A case report and literature review. Oncol Lett 9: 833-836, 2015.

3. Lin JJ and Lin F: Two entities in angiolipoma. A study of 459 cases of lipoma with review of literature on infiltrating angiolipoma. Cancer 34: 720-727, 1974.

4. Howard WR and Helwig EB: Angiolipoma. Arch Dermatol 82: 924-931, 1960.

5. Jiang L, Wang YL, Zhou YM, Xie BX, Wang L, Ding JA and Jiang GN: Bronchial angiolipoma. Ann Thorac Surg 88: 300-302, 2009.

6. Bowen JT: Multiple subcutaneous hemangiomas, together with multiplelipomas, occurring in enormous numbers in an otherwise healthy,muscular subject. Am J Med Sci 144: 189-192, 1912.

7. Sciot R, Akerman M, Dal Cin P, De Wever I, Fletcher CD, Mandahl N, Mertens F, Mitelman F, Rosai J, Rydholm A, et al: Cytogenetic analysis of subcutaneous angiolipoma: further evidence supporting its difference from ordinary pure lipomas: a report of the CHAMP Study Group. Am J Surg Pathol 21: 441-444, 1997.

8. Arenaz Búa J, Luáces R, Lorenzo Franco F, García-Rozado A, Crespo Escudero JL, Fonseca Capdevila E and López-Cedrún JL: Angiolipoma in head and neck: Report of two cases and review of the literature. Int J Oral Maxillofac Surg 39: 610-615, 2010.

9. Gonzalez-Crussi F, Enneking WF and Arean VM: Infiltrating angiolipoma. J Bone Joint Surg Am 48: 1111-1124, 1966.

10. Guzey FK, Bas NS, Ozkan N, Karabulut C, Bas SC and Turgut H: Lumbar extradural infiltrating angiolipoma: A case report and review of 17 previously reported cases with infiltrating spinal angiolipomas. Spine J 7: 739-744, 2007.

11. Muraoka M, Oka T, Akamine S, Nagayasu T, Iseki M, Suyama N and Ayabe H: Endobronchial lipoma: Review of 64 cases reported in Japan. Chest 123: 293-296, 2003.

12. Gerard N and Schultz DA: Angiolipoma of the upper lip: Report of a case. J Oral Maxillofac Surg 67: 1340-1341, 2009.

13. Kline ME, Patel BU and Agosti SJ. Noninfiltrating angiolipoma ofthe mediastinum. Radiology175:737-738, 1990.

14. GrivasTB,Savvidou OD,Psarakis SA,LiapiG,Triantafyllopoulos G, Kovanis I, Alexandropoulos P and Katsiva V: Forefoot plantar multilobular noninfiltrating angiolipoma: a case report and review of the literature. World J Surg Oncol 6: 11, 2008.

15. Sánchez Aniceto G, Salván Saez R and García Peñin A: Angiolipoma of the cheek: Report of a case. J Oral Maxillofac Surg 48: 512-515, 1990 .

16. Weill A, del Carpio-O’Donovan R, Tampieri D, Melanson D and Ethier R: Spinal angiolipomas: CT and MR aspects. J Comput Assist Tomogr 15: 83-85, 1991

17. Nassiri AH, Dutau H, Breen D, Colchen A, Quiot JJ, Nguyen B, Vergnon JM; GELF Groupe d'Endoscopie de Langue Française: A multicenter retrospective study investigatingthe role of interventional bronchoscopictechniques in the management of endobronchiallipomas. Respiration75:79-84, 2008.

18. Choi JC, Yu CM, Ryu YJ, Jeon K, Choi KA, Kwon OJ and Kim H: The role of endoscopic surgery for completely obstructive endobronchial benign tumor. Korean J Intern Med 21: 15-19, 2006.

19. Lamprecht B, Hutarew G, Porsch P, Wegleitner B and Studnicka M: Successful bronchoscopic cryorecanalization in a case of endobronchial lipoma. Diagn Ther Endosc 2011: 845686, 2011.

20. Gelabert-González M and García-Allut A: Spinal extradural angiolipoma: Report of two cases and review of the literature. Eur Spine J 18: 324-335, 2009. 